\title{
Spatial dispersion of housing units as an important factor influencing long-term care operational costs
}

Over $90 \%$ of seniors prefer to age in place, which is an idea supported by the European semesters on long-term care strategic plans for member states, but they do not have the necessary innovation to improve the living of the elderly in a properly built environment with sustainable financing. The spatial dispersion of housing and density in a functional area should be particularly taken into consideration by facilities' managers and medical care institutions offering housing, healthcare and other services for the elderly in planning the built environment and other facilities for seniors because the costs of logistics (material transport, nurse workload, costs of other service providers, and transport of seniors in the case of daily programmes) greatly depend on it. Using data from a care centre in a Hungarian municipality, we simulated and optimised home healthcare routing and scheduling in various scenarios of spatial dispersion and changing density of clients. We modelled the rounds of caregivers visiting seniors in homecare as a multiple travelling salesman problem, and the solutions show the necessary workforce and service time requirements. The tool that enabled us to study the outputs of scenarios might help professionals forecast and plan for coming changes in the costs of nursing services caused by the growing number of seniors that may need help in maintaining their independence as long as possible, taking into account that the density and dispersion of households are also changing.

Keywords: housing, long-term care, service scheduling, spatial dispersion, functional region 


\section{Introduction}

According to long-term care studies, the elderly frequently state that they prefer to remain in their own homes rather than opt for other living options (Keenan, 2010; Gillsjö et al., 2011). Over $90 \%$ of adults over sixty-five would prefer to age in place; that is, to remain in their current residence or their place of choice as long as possible, as also shown in recent studies in Slovenia (Kavšek \& Bogataj, 2015, 2016). New technologies can facilitate this, whereby communication technologies and improvements in healthcare, wellness, and safe and secure environments are experiencing the most important innovations. For example, new caregiving technologies such as smart phones, websites and tablets help those caring for the elderly provide services in the most effective way. European semesters (e.g., for Slovenia see: Council recommendation on the National reform programme 2014 of Slovenia and delivering a Council opinion on the Stability programme of Slovenia, 2014; Council of the European Union, 2014) support this idea in the health and care sector, but currently only few plans for housing improvements support this goal by stimulating innovation that will enable this shift from institutionalised care to homecare in properly designed housing units. We need to improve the living of the elderly in a properly built environment with sustainable financing. The spatial dispersion of housing should be particularly considered in planning the built environment and other facilities for seniors because logistical costs increase with increasing dispersion of households in which services are provided. Facilities' managers and medical care institutions offering housing, healthcare and other services for the elderly should consider the costs of material transport, employment of nurses and other service providers, and the transport of seniors in daily programmes, which depend on the dispersion of housing units. Daily home healthcare may be labour- and staff-intensive, and therefore feasible routing and scheduling are essential for an acceptable trade-off between logistical costs and the satisfaction of seniors.

Compared to other current challenges of society - such as climate change and the financial crisis - ageing can be fairly accurately forecasted and its potential impact predicted; it offers policymakers the opportunity to prepare for changes in the demographic structure (OECD, 2015). As stated in the report Ageing in cities, "Better urban policy approaches will help us to improve the quality of life for residents at all ages" (OECD, 2015: 18) and, to facilitate this, strategies have been drawn up that are considered to be effective for mitigating risks and making the best use of opportunities. Table 1 summarises these key strategies and sub-strategies, which are broken down into more precise approaches.
Certain sub-strategies of key strategies 5 and 6 - such as "Promote affordable housing through innovative schemes to provide social housing. Promote policies to provide care at home. Reformulate the appropriate location for urban infrastructure, to optimise land use. Implement a toolkit for effective public investments" (OECD, 2015: 68) - require a holistic approach to planning and development. This article elucidates the relation between housing supply and care at home, and estimates the factors that can influence the cost of homecare delivery. Due to the ageing process, the need for long-term care and accessible houses will grow significantly, and a home-based independent living model would require a properly built accessible environment. Current housing units will struggle to meet this demand, and according to a European Commission report (2015b) some 70 to $80 \%$ of houses in the UK and $90 \%$ in Germany are not suitable for independent living because they contain accessibility barriers for people with emerging functional impairments and chronic conditions, and are not equipped with the necessary digital infrastructure required for future connected care services. As also stated in this report, in Germany alone the need for age-friendly houses already exceeds 2.5 million units today. In the Netherlands, there is an estimated need to convert 330,000 homes into age-friendly dwellings. In eastern Europe there is a lack of reporting about the numbers regarding these problems. In Hungary, there is no specified policy approach to tackle the demographic change, neither by creating an integrated long-term care system nor age-friendly urban plans. There is very little supply of social housing - approximately thirty-five thousand units (Hungarian central statistical office, 2016), of which a limited number are dedicated for the retired population in need of housing with care: an estimated five thousand units (Csehák, 2003). There is a continuously growing need for housing with care services as the population grows older, whether it is their own home or a residential care setting such as a retirement or elderly home. This trend is already characterised by the fact that there are waiting lists for elderly homes that include 160 to 170 names of frail elderly citizens that submitted their application to move into the elderly homes in their municipalities, but it takes them one and a half to two years before they might move in if they are eligible (Rosta, 2014). In practice, these applicants on waiting lists are helped via homecare services or informal care, but these solutions are not optimal or sustainable with the current pace of population ageing. When the local authorities face the choice between building more or less dispersed housing units in retirement villages, building urban retirement settlements or arranging care in existing homes, they will have to compare the construction costs with the costs of providing adequate services, including investments in daily logistics and an accessible urban environment. 
Table 1: Suggested key strategies and sub-strategies for ageing in cities.

\begin{tabular}{ll}
\hline Key strategies & Sub-strategies \\
\hline $\begin{array}{l}\text { 1. Develop a long-term vision } \\
\text { 2. Develop indicators }\end{array}$ & $\begin{array}{l}\text { Cities at different stages of the demographic transition can develop a vision for their future focusing } \\
\text { on the most critical challenges they face. }\end{array}$ \\
\hline & $\begin{array}{l}\text { These visions should include quantitative assessment, using internationally comparable indicators. } \\
\text { living environment, and community activity sectors. }\end{array}$ \\
\hline $\begin{array}{l}\text { 3. Promote health for all ages } \\
\text { Cities choose the best mix of indicators for the phase in the ageing process applicable to them. }\end{array}$ & Promote health measures using information technologies. \\
\cline { 2 - 2 } & Encourage walking as a preventative strategy for optimising health.
\end{tabular}

City governments can become a model for retaining older employees.

4. Increase older people's engagement in the labour market and in social activities

Provide access to jobs by expanding public transport.

Promote entrepreneurship among older age groups.

Encourage older people to volunteer in their communities.

Develop activities that bring together younger and older people.

Promote affordable housing through innovative schemes to provide social housing, including publicprivate partnerships, and increase the supply of smaller units of housing.

5. Provide affordable housing in accessible environments
Improve access to employment and public and private services by public transport.

Promote policies to provide care at home.

Reformulate the appropriate location for urban infrastructure to optimise land use.

6. Redesign urban areas to increase Invest in improving walkability in urban areas. Integrate strategies across different policy areas to attractiveness and well-being encourage improvements in a city's social and economic sustainability.

Implement a toolkit for effective public investments.

Source: OECD (2015).

In our earlier study (Szander et al., 2016), we examined the scheduling of home healthcare nurses in the same functional area from a different perspective. The functional area of $\mathrm{Zal}-$ aegerszeg is $99.98 \mathrm{~km}^{2}$ and the number of patients receiving home healthcare is sixty-seven in the current study; this means there are 0.67 housing units to visit per $\mathrm{km}^{2}$. We used data on patient locations and care needs provided by the Zalaegerszeg Long-Term Care Centre. The aim of that study was to measure the impact of service quality improvement by assigning the elderly to a fixed appointment time, instead of leaving them waiting half a day for the arrival of the nurse. We found that aiming to balance the uncertainty of transport by creating more widely spread appointment times results in more idle time during the nurses' working day and an increased human workforce requirement. We also observed significant differences in the nurses' workload (the total length of all caretaking activities assigned to each of them) due to the patient-nurse assignment method used by the care provider. Based on the previous results, we improved our model: we added the linking of patients to a nurse as a variable, and therefore the number of nurses became part of the optimisation process (i.e., to be minimised).

\section{Methodology}

The demand density and dispersion of clients in the functional region (i.e., knowing the dispersion of distances between a pair of clients and the density of clients in a functional area) offers an opportunity to develop scenarios to estimate the impact of those two parameters on the costs of services. In the functional area of a municipality, service provision (e.g., delivering home healthcare for the elderly) should cover the entire functional area, even the outskirts of a town. The basic input for developing a distribution system is the population density of a functional area and the proportion of those that need the services. The density of population is the ratio between the annual average population and the area of a functional region, excluding inland waters (Statistical office of the European Communities, 2016). In general, the higher density induces lower unit costs of services because it means more potential customers for the given area. The profile of long-term care users shows a quite homogenous group of consumers; their need arises from their health status and their abilities to engage in activities of daily living and instrumental activities of daily living. This homogeneity offers the possibility to make a reasonably accurate esti- 

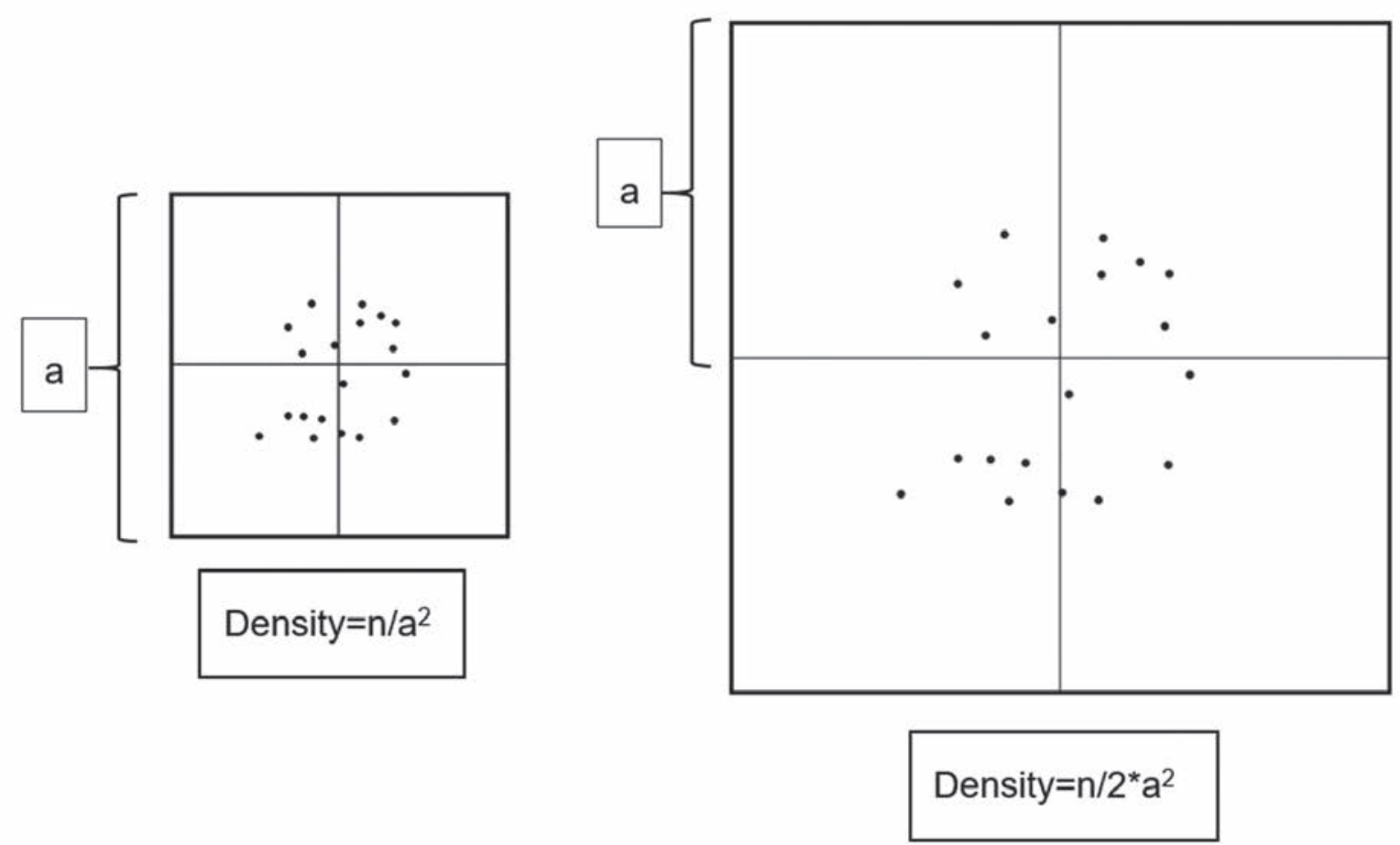

Figure 1: Density and changing the size of the service area (source: authors).

mation of the expected number of long-term care-dependent persons (Czibere \& Gál, 2010). Because the costs of logistics in distribution systems depend highly on the variance of distances between two adjacent clients, the dispersion of these distances is taken into consideration in the planning process. The dispersion describes how the points are spread out in a given area and is measured by variance or standard deviation of the distances observed (Briggs, 2010). From the logistics point of view, the favourable dispersion has a low standard deviation of distances (Chopra, 2003).

The planning of services for the elderly should consider these measures. Because the ageing process is not taking place uniformly across all regions, the expected number of service users can be forecasted by using the ageing index and population data, but this approximation will not provide sufficient information from a spatial perspective. There are numerous examples in urban settings where the proportion of seniors is typically high (e.g., the number of elderly stuck in city centres from where the younger population was drained due to the suburbanisation process of larger cities; Kučera \& Burcin, 2010). In other cases, the proportion of senior cohorts can be measurably higher in underdeveloped urban peripheries than in advanced recently developed outskirts - which is a consequence of social inequalities (Szirmai et al., 2010). In some countries, scholars have documented the so-called naturally occurring retirement communities, also known as rural destinations of elderly migrants, which are "deliberately occupied but

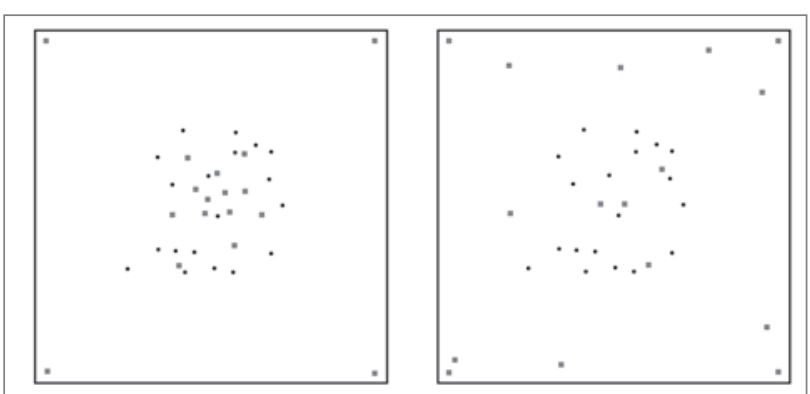

Figure 2: Growing demand with lower (left) and higher (right) standard deviation of distances (source: authors).

unplanned elder residences" (Golant, 2002: 67). Altogether, the likelihood of the demand for help or care services emerging from such areas is much higher than the average age of the population in the broader area would suggest.

When service planning is based on the density of clients in a given service area (number of patients $/ \mathrm{km}^{2}$ ), changing one of the indicators will necessarily affect the other. Figure 1 shows what happens if the service provision is planned for a larger area, but the number of clients is the same, while also maintaining their pattern of location. According to the mathematical ratio in this calculation, the distance between the points changes proportionally with the density of population, and therefore it can be concluded that the average distance of points will also change with the change in the size of the area. 
Table 2: Design scenarios of various housing dispersion and the number of patient requests.

\begin{tabular}{lll}
\hline Design scenario 1 & Design scenario 1.1 & Design scenario 1.2 \\
\hline Predominately apartment buildings & $\begin{array}{l}\text { Density A } \\
\text { Dispersion B }\end{array}$ & $\begin{array}{l}\text { Density D } \\
\text { Dispersion B }\end{array}$ \\
\hline Design scenario 2 & Design scenario 2.1 & Design scenario 2.2 \\
\hline Predominately family houses & Density A & Density A \\
& Dispersion C & Dispersion B \\
\hline
\end{tabular}

The variety of settlement structures and designs requires a better understanding of the various spatial patterns and densities of demand. Figure 2 presents two such cases in which the demand for homecare grows equally in absolute numbers (represented by grey squares), but the locations follow two very different layouts, and therefore they would need different resource allocation. For this purpose, we developed two design scenarios to experiment with the impact of changing the layout or the number of patients. Design scenario 1 is the case in which the locations of the elderly receiving home healthcare are randomly distributed in a town, mostly in the condominium type of housing. Then, in design scenario 2 , we consider the same town with the same density (person $/ \mathrm{km}^{2}$ ) of patients, but in a more spread-out arrangement; that is, the standard deviation of distances is higher. After that it is possible to add a twist and examine the scenarios differently: we retain the value of dispersion and combine it with different values of density. Table 2 summarises these ideas.

The mathematical formalisation of the problem is as follows. We used the multiple travelling salesman problem approach, so that every patient would be visited once along the shortest possible route. The mathematical model is based on our previous work (Szander et al., 2016), but there we assigned nurses based on the idea that every patient wants to receive help from the nurse he or she has got used to, which is not the case here. The multiple travelling salesman problem approach was modified and formalised as described in Tolga Bektas (2006). The procedure was used to find the shortest route for visiting patients. Equations 1-3 describe the assignment part, complemented with the sub-tour elimination constraint (Equation 4) based on the Miller-Tucker-Zemlin formulation (Miller et al., 1960). The integer programming for the multiple travelling salesman problem is described in the formulations below.

Consider a graph $\mathrm{G}=(\mathrm{A}, \mathrm{L})$ where $\mathrm{A}$ is the set of $n$ nodes $(i, j=1,2, \ldots n)$, presenting $n$ homes of patients in long-term care in the municipality, known by addresses and geocodes on the map, and $L$ is the set of edges $\left(l_{i, j} \varepsilon L\right)$, marked on the roads of the map between all possible pairs $(i, j)$ of nodes, on which the minimum values of time spent travelling between $c_{i, j}$ are known. Therefore to each pair of nodes $(i, j)$ the shortest edge $l_{i, j} \varepsilon L$ is defined by travel time $c_{i, j}$. Each nurse moves between the patients' homes, starting and returning to the Zalaegerszeg Long-Term Care Centre. Nurses spend $90 \%$ of their working day travelling on these roads and $10 \%$ on preparation and writing reports at the municipal nursing home.

The objective function (Equation 1) is to minimise the total number of nurses based on the constraints (Equations 2-6) requiring that the duration of routes $c(k)$ be equal to or smaller than the $90 \%$ of nurses' daily workload ( 8 hours/day). The route of nurse $k$ is the sum of time distances between the patients visited $\left(c_{i j}\right)$ and the prescribed care time $\left(w_{j}\right)$ plus the outbound and inbound travel time from/to the care centre).

Minimize $m$

$$
\begin{gathered}
c(k)=\sum_{i=0}^{n}\left(\sum_{i=0}^{n} c_{i j} x_{i j k}+x_{i j k} w_{j k}\right)+c_{i 0 k} x_{i j k} \leq 0,9 * 8 \quad k=1,2 \ldots \mathrm{m} \\
x_{i j k}=0,1 \\
c_{i j}=s_{i j} * d_{i j}
\end{gathered}
$$

Variable $x_{i j k}$ equals 1 if the $k^{\text {th }}$ nurse goes immediately from $i$ to $j$, and 0 otherwise. $d_{i j}$ is the shortest distance between $i$ and $j$ by roads, and $s_{i j}$ is the optimal speed that it is possible to reach on the given road. All $m$ nurses start their daily circular route at the Zalaegerszeg Long-Term Care Centre denoted by node 0 and they return to the same location after less than eight hours of work, after visiting the last patient.

Equations 3 and 4 were added to the traditional travelling salesman problem formulation to ensure that exactly $m$ nurses depart from and return to the Zalaegerszeg Long-Term Care Centre. The nurse must leave location $i$ after the care tasks are performed, and goes on to only one location $j$ out of the remaining locations, as shown in Equation 5. 


$$
\begin{aligned}
& \sum_{k=1}^{m} \sum_{j=1}^{n} x_{0 j k}=m \\
& \sum_{k=1}^{m} \sum_{i=1}^{n} x_{i 0 k}=m
\end{aligned}
$$

$$
\sum_{j=1}^{n} x_{i j k}=1 \quad \forall i
$$$$
\forall \mathrm{k}
$$

$$
\sum_{i=1}^{n} x_{i j k}=1 \quad \forall j
$$$$
\forall \mathrm{k}
$$

Equation 6 requires that if the nurse is at a particular location at a given moment, he or she could have come from only one of the previous locations to the present location. The sub-tour elimination constraint (Equation 7) is a vital part of the travelling salesman problem formulation; it is allowed to have only one tour, a Hamiltonian circuit for each nurse, covering all locations to which the nurse is allocated, instead of two or more separate tours adding up to cover all sites. Therefore "dummy" variables $u_{i}$ are introduced, which represent the sequence in which location $i$ is visited, whereas the values of $u_{i}$ are arbitrary real numbers and $p$ denotes the maximum number of nodes visited by any nurse (Bektas, 2006).

$$
\begin{gathered}
\mathrm{u}_{\mathrm{i}}-u_{\mathrm{j}}+\mathrm{p} x_{\mathrm{ijk}} \leq \mathrm{p}-1 \quad 0 ; \quad \mathrm{s}=\mathrm{i}, \mathrm{j} \\
x_{i j k}=0,1 \\
i=0 \ldots n-1 \\
j=1 \ldots n \\
\forall \mathrm{k} ; \quad k=1,2, \ldots, m
\end{gathered}
$$

\section{Implementation and results}

We optimised each case (different densities and different dispersions) for the smallest possible workforce (number of nurses). In order to obtain better results, we waived the principle of assigning patients to nurses. In real-life calculations this is an important constraint because seniors tend to become attached to or get used to one carer, and therefore it is reasonable for the service to be delivered by the same caregiver. Because this study focuses on finding the smallest amount of workforce used to perform the care tasks, we did not allow this option. The problem could easily be extended and solved if we added some obligatory nurse-patient assignment rules, but the optimal value would be much higher. In further research, it is possible to calculate how much the patient should pay for this extra bonus from the difference in the value of criterion function. We created a constraint of 430 minutes of workload including travel, which represents approximately $90 \%$ of the total capacity, and the remaining $10 \%$ create buffer time for unforeseen events. The workload is not the same throughout the week; we optimised the busiest day when most patients are scheduled for care.

In the simulation procedure, we could first decrease the need for nurses from eleven to seven at the original dispersion $(\sigma=1.811)$, but this decrease should be acknowledged due to the increased speed (nurses travel by bus and walk, and therefore their speed is considerably lower) and the changed focus of assigning carers. The results in the case of different dispersions are presented in Figure 3, which also shows the time spent travelling as a percentage of the working period. Figure 4 presents the routes of the seven nurses after the optimisation. To create variations for design scenario 2.1, we increased the standard deviation of the travel times between each point to represent different dispersion. Throughout the calculations, this resulted in different values in the cost matrix as the input of the constraint (Equation 2). Table 3 summarises the results and the running time of the solver to perform the optimisation (in minutes). In the initial scenario, the longest distance measured between two points was 8.7 minutes and the standard deviation of travel times $(\sigma)$ was 1.8115 , whereas the travel time between the two farthest points in the scenario with the highest hypothetical dispersion that we examined $(\sigma=9.0577)$ was 43.5 minutes. We considered this to still be realistic; for example, in a medium-sized city it is possible to drive for about three-quarters of an hour between its two most distant points.

Theoretically, the $\sigma$ of travel time may be caused by either the change in speed or change in distance $\left(c_{i j}=s_{i j}{ }^{*} d_{i j}\right)$, as described in the mathematical formalisation. Because this article does not aim to provide a decision tool for choosing transport means, we treat travel time as a compound measure (i.e., describing a variety of cases) and use $\sigma$ for benchmarking across different cases, and therefore our model is applicable for supporting either transport means or location planning decisions. The proportion of time spent travelling in the total time rose steadily with the increase in $\sigma$. In the scenarios examined, the lowest value of standard deviation was $\sigma=0.9057$, where the locations are less dispersed or the nurses are able to travel at a rather fast pace $(48.85 \mathrm{~km} / \mathrm{h}$ on average - which is quite impossible in traffic), but this scenario did not result in further reduction in the number of nurses. We also simulated an "extreme" situation, in which patients' locations are concentrated very close to each other; that is, it takes only one minute to move from one patient to another, and therefore $\sigma$ is extremely low $(\sigma=0.132$; this is the standard deviation between 1 and 0 minutes for fifty-five patient locations). Because the total 


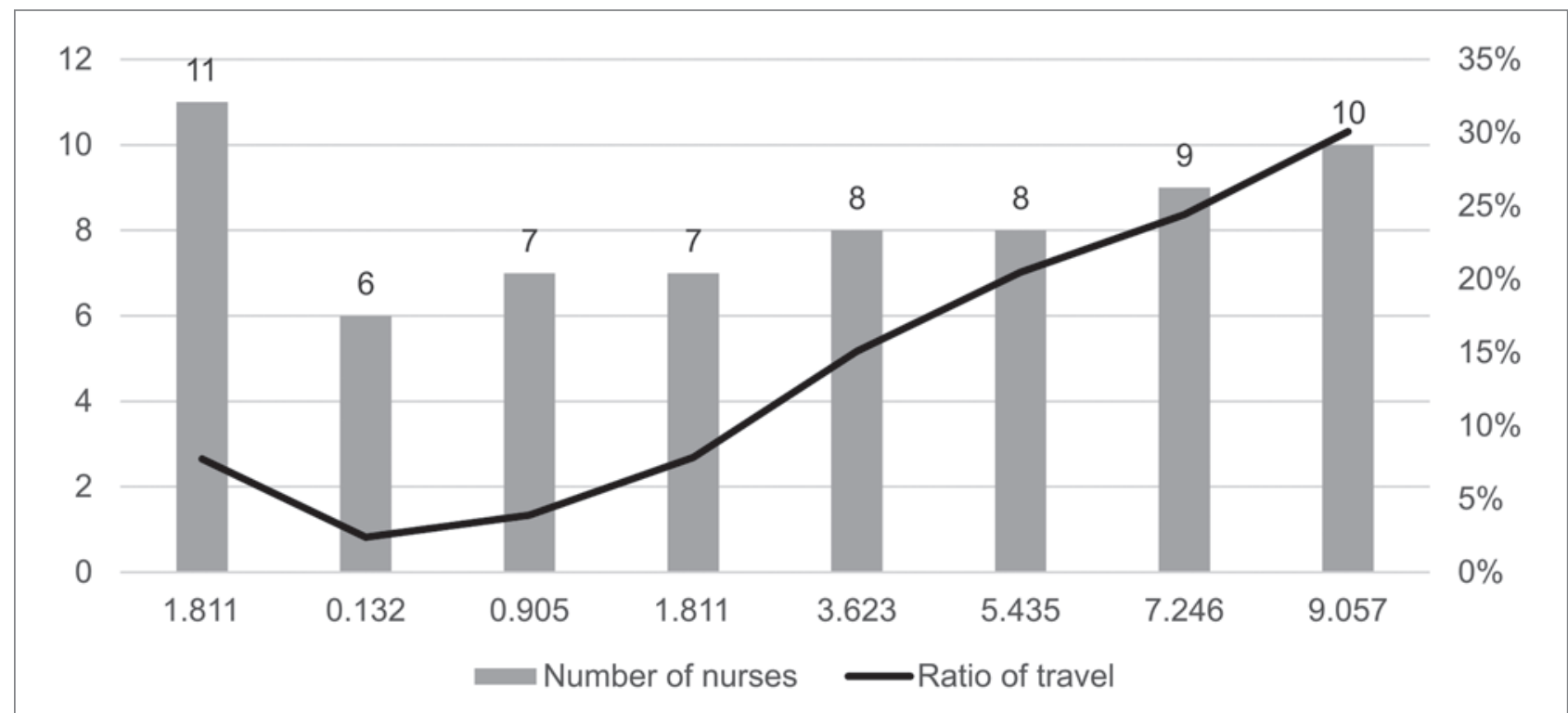

Figure 3: Required number of nurses and the dispersion of patients (source: authors).

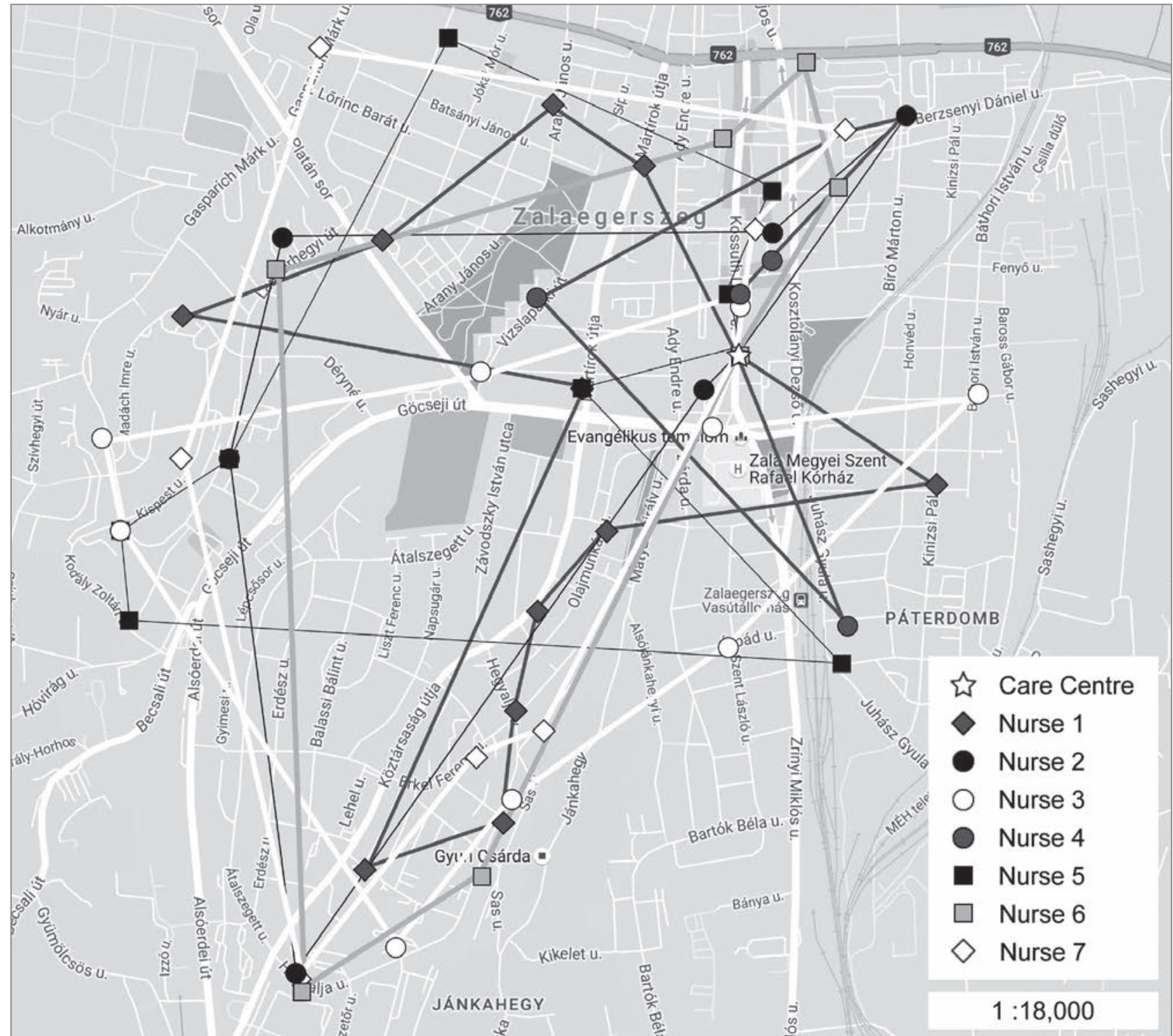

Figure 4: Optimal routing for seven nurses according to design scenario 1.1 (source: authors). 
Table 3: Computation and results for design scenario 1.1 and variations for design scenario 2.1.

\begin{tabular}{llllllll}
\hline Scenario & $\sigma$ of travel time & Total distance & Total time & $\begin{array}{l}\text { No. of } \\
\text { nurses }\end{array}$ & Average time & $\begin{array}{l}\text { Runtime of } \\
\text { solver }\end{array}$ & Ratio of travel \\
\hline Initial & 1.811 & 210.9 & $2,724.9$ & 11 & 247.72 & & $7.73 \%$ \\
\hline 2.1 & 0.132 & 55 & 2,527 & 6 & 422.16 & 9.98 & $2.4 \%$ \\
\hline 2.1 & 0.905 & 107.75 & $2,765.75$ & 7 & 395.10 & 21.61 & $3.90 \%$ \\
\hline 1.1 & 1.811 & 219.8 & $2,804.8$ & 7 & 400.68 & 13.67 & $7.84 \%$ \\
\hline 2.1 & 3.623 & 445.2 & $2,950.2$ & 8 & 368.78 & 22.08 & $15.09 \%$ \\
\hline 2.1 & 5.435 & 654 & 3,194 & 8 & 399.25 & 5.8 & $20.48 \%$ \\
\hline 2.1 & 7.246 & 832.8 & $3,410.8$ & 9 & 378.98 & 7.56 & $24.42 \%$ \\
\hline 2.1 & 9.057 & $1,146.5$ & $3,813.5$ & 10 & 381.35 & 6.56 & $30.06 \%$ \\
\hline
\end{tabular}

Source: Authors.

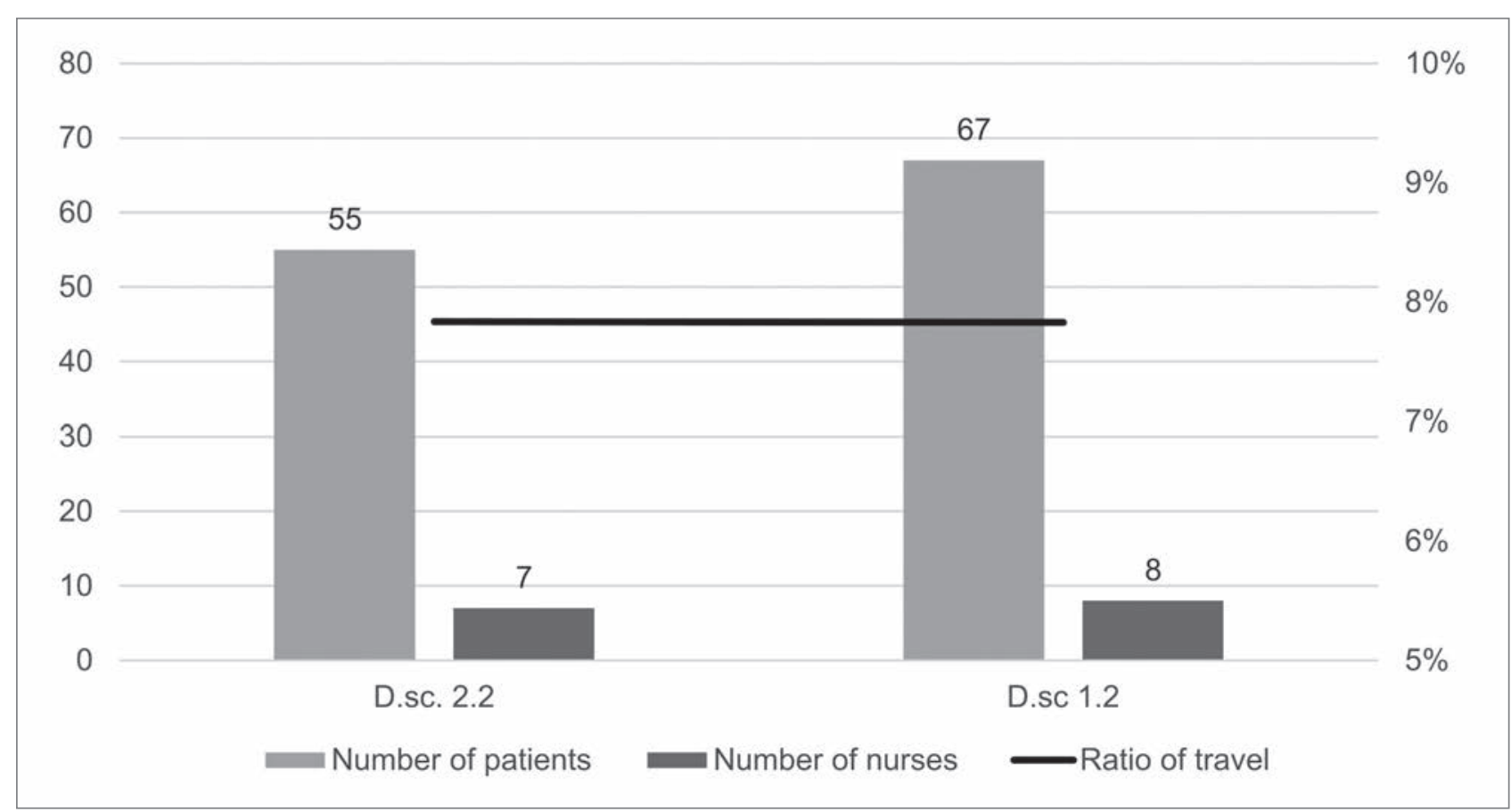

Figure 5: Two scenarios with the same ratio of travel and different number of patients and nurses (source: authors).

Table 4: Computation and results for design scenarios 1.2 and 2.2.

\begin{tabular}{lllllll}
\hline Scenario & No. of patients & Total distance & Total time & No. of nurses & Average time & Portion of travel \\
\hline 2.2 & 55 & 219.8 & $2,804.8$ & 7 & 400.685 & $7.836 \%$ \\
\hline 1.2 & 67 & 261.8 & $3,343.8$ & 8 & 417.975 & $7.829 \%$ \\
\hline
\end{tabular}

Source: Authors.

length of the prescribed care for the patients studied was 2,472 minutes, with the $\sigma$ of locations close to zero we could lower the required number of care personnel to six.

In the second scenario, we worked with a different volume of demand representing the increased number of patients/ $\mathrm{km}^{2}$. The original distance matrix was adjusted for the case of lower demand to have exactly the same standard deviation of distances as the case with a higher number of patients scheduled: $\sigma=1.8115$. To create a larger number of patients and still use real data, the scenario included the prescribed care time requirements of the patients that were not scheduled on the busiest day. Microsoft Excel solver ran for 13.66 minutes. As seen in Figure 5 and Table 4, the increase in the number of patients requires more workforce, but the portion of travel did not show a significant difference with the same dispersion. The number of patients increased by $21.8 \%$, which will happen by 2030, according to EUROSTAT projections (European Commission, 2015a). With optimal scheduling, travel time as a proportion of total time was actually reduced by $0.007 \%$. 


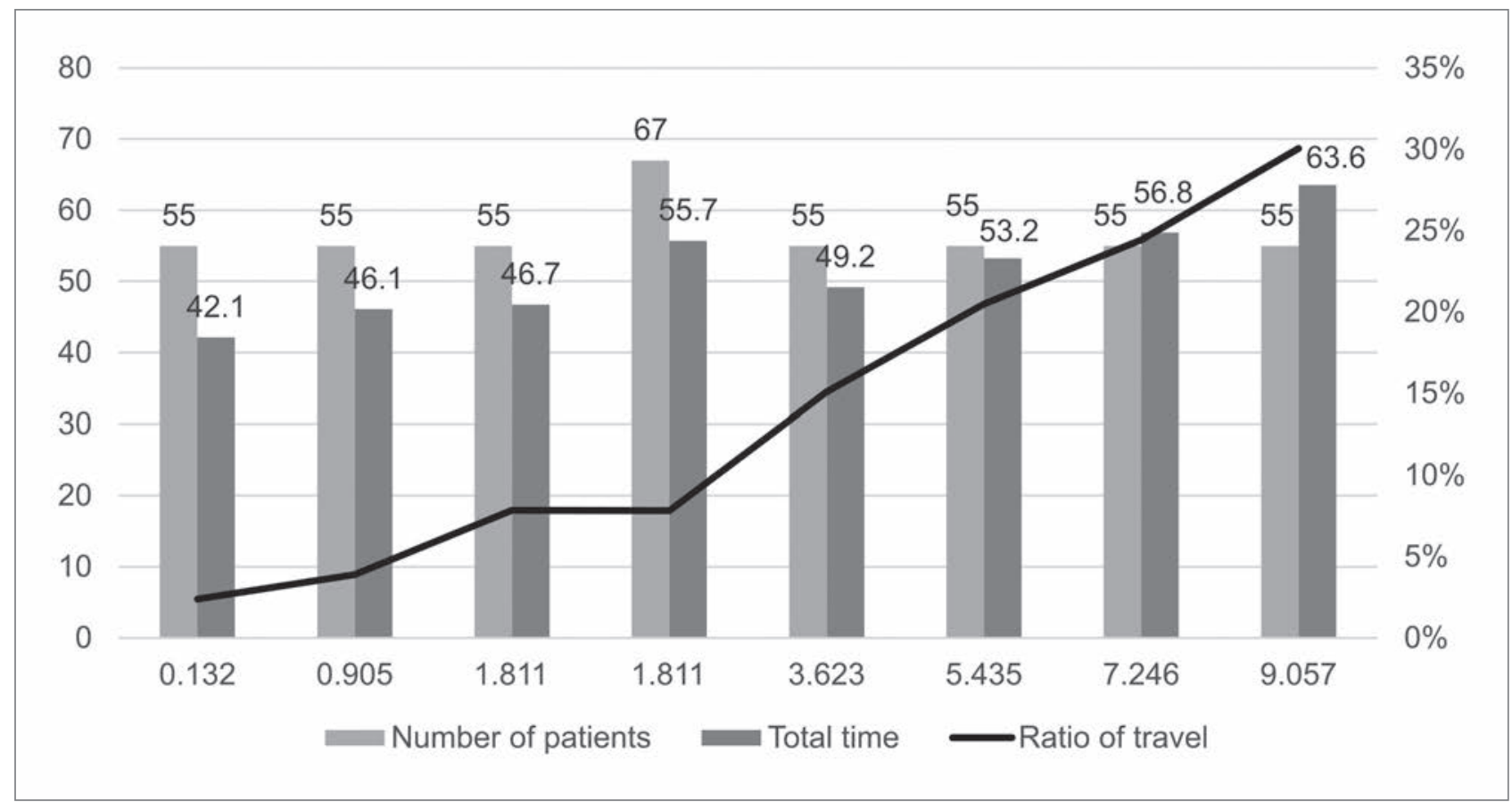

Figure 6: All scenarios of demand density and dispersion studied in terms of the travel time ratio (source: authors).

\section{Conclusion}

The optimisation of routing for home healthcare workers visiting frail elderly patients can help reduce the cost (in our case, measured in time and the number of nurses employed) connected with the care delivered. Admittedly, this also depends on the means of transport the caregivers use and the spatial dispersion of seniors. This article presents various scenarios of spatial dispersion and demand density in a town with a county's rights, using real data of patients' location and prescribed care needs. From a logistics point of view, the planning of a distribution system can be assisted by estimations of demand and spatial distribution. In practice, a change in one usually changes the other, and therefore in our study scenarios we aspired to separate the effect of these variables to measure their impact on healthcare service delivery. The literature on home healthcare delivery problems draws attention to various aspects of routing and scheduling processes, but lacks two very distinct features: the effect of different dispersion patterns and the choice of transport mode, which are not considered as variables of the objective function, but only as predetermined inputs of the cost function. Bearing this in mind, the study scenarios were created to demonstrate the role of land-use patterns in long-term care delivery, therefore identifying a relation between the challenges of the demographic change and urban development. To optimise the routing, we used the multiple travelling salesman problem approach, with the objective of minimising the number of nurses by constraining their workload. Two scenarios were created for the estimations: one was created to represent an urban design in which the dispersion of housing is lower (more condominium flats), and the other scenario represents a neighbourhood in which the housing is more spread out in the area and more likely to consist of detached houses (similar to the suburbs and outskirts of a city). We found that the spatial dispersion of locations to be visited has a significant impact on the proportion of travel time in the total service delivery time. The travel time increases proportionally with the change in the standard deviation of the distance between patients' locations.

Then we examined the first scenario again, but with a fixed spatial dispersion, and we changed the number of locations. In this case, we found that the time requirement of the service delivery was not significantly influenced by the number of patients. To schedule all of the patients, it was necessary to add one extra nurse to the home healthcare delivery staff, but the proportion of the time spent travelling did not change significantly in the total service delivery time. In Figure 6, all of the scenarios studied are shown together, and in this way one can observe that the impact of the higher number of scheduled patients on the proportion of travel time is very low, whereas the spatial dispersion (standard deviation measured in $\sigma$ of travel time) gradually increases the required travel time, ending up at $30 \%$ in the last case studied. The additional staff member was inevitable because the prescribed care needs can legally extend up to four hours a day, which is an indecomposable time unit (i.e., it is not possible to allocate only some part of it to some of the nurses). The solver did not find a feasible solution in the case of the same number of nurses. Nevertheless, in practice this is highly unlikely because frail elderly patients 
that need around four hours of care seek out care options other than homecare, but we wanted to keep the solution feasible in the current policy environment.

Based on the results of our simulation, we acknowledge the logistical aspects of healthcare delivery of a long-term care provider organisation. Generally, it is not possible to influence the number of patients' requests emerging due to the ageing process; decision-makers should consider the variables that can be controlled to some extent. Spatial dispersion might be influenced by urban policies and building plans, and therefore we emphasise the importance of taking this into consideration. Because the standard deviation of travel times had a significant impact on the labour force requirement, as demonstrated in this study, this measure can be useful for both transport mode and facility location decisions. This novel approach can help urban planners account for the outcomes of development decisions, whether these involve creating better infrastructure connections by bicycle or public transport, or selecting locations for new affordable housing units.

\section{Norina Szander}

MEDIFAS: Mediterranean Institute for Advanced Studies, Vrtojba,

Slovenia, and Faculty of Organisation Studies in Novo mesto, Novo

mesto, Slovenia

E-mail: norina.szander@medifas.net

Lorenzo Brian Ros-McDonnell

Business Engineering Research Group, Universidad Politécnica

Cartagena, Cartagena, Spain, and MEDIFAS, Mediterranean Institute for Advanced Studies, Vrtojba, Slovenia

E-mail: lorenzo.ros@upct.es

\section{Marija Bogataj}

MEDIFAS: Mediterranean Institute for Advanced Studies, Vrtojba, Slovenia, and Faculty of Organisation Studies in Novo mesto, Novo mesto, Slovenia

E-mail:marija.bogataj@guest.arnes.si

\section{References}

Bektas, T. (2006) The multiple traveling salesman problem: An overview of formulations and solution procedures. Omega, 34(3), pp. 209-219. DOI: 10.1016/j.omega.2004.10.004

Briggs, R. (2010) Descriptive statistics for spatial distributions - review. Available at: http://www.utdallas.edu/ briggs/ (accessed 12 Jun. 2016).

Chopra, S. (2003) Designing the distribution network in a supply chain. Transportation Research Part E: Logistics and Transportation Review, 39(2), pp. 123-140. DOI: 10.1016/S1366-5545(02)00044-3

Council of the European Union (2014) Council recommendation of 8 July 2014 on the National Reform Programme 2014 of Slovenia and delivering a Council opinion on the Stability Programme of Slovenia, 2014 (2014/C 247/22). Available at: http://ec.europa.eu/europe2020/ pdf/csr2014/csr2014_council_slovenia_en.pdf (accessed 20 Mar. 2017).

Csehák, J. (2003) Retirement homes or elderly homes? Available at: http:// www.parlament.hu/irom37/3957/3957-001.htm (accessed 20 Mar. 2017).
Czibere, K. \& Gál, R. I. (2010) The long-term care system for the elderly in Hungary. Available at: http://www.ancien-longtermcare.eu/node/27 (accessed 12 Jun. 2016).

European Commission (2015a) The 2015 Ageing report - economic and budgetary projections for the 28 EU member states (2013-2060). Available at: http://ec.europa.eu/economy_finance/publications/ (accessed 12 Jun. 2016).

European Commission (2015b) Innovation for active \& healthy ageing. Final report. Available at: https://ec.europa.eu/research/innovationunion/pdf/active-healthy-ageing/ageing_summit_report.pdf (accessed 12 Jun. 2016).

Gillsjö, C., Schwartz-Barcott, D. \& von Post, I. (2011) Home: The place the older adult can not imagine living without. BMC Geriatrics, 11(1), pp. 1-10. DOI: 10.1186/1471-2318-11-10

Golant, S. M. (2002) Deciding where to live: The emerging residential settlement patterns of retired Americans. Generations, 26(2), p. 66.

Hungarian Central Statistical Office (2016). Real property of the municipalities. Available at: http://www.ksh.hu/docs/hun/xstadat/xstadat eves/i_zri001b.html (accessed 20 Mar. 2017).

Kavšek, M. \& Bogataj, D. (2015) Smernice kakovosti dolgotrajne oskrbe. In: Ros-McDonnell, L., Bogataj, D. \& Kavšek, M. (eds.) Dolgotrajna oskrba: izzivi in priložnosti: oskrbovalni in bivalni vidiki, pp. 1-27. Šempeter pri Gorici, MEDIFAS and Ljubljana, Skupnost socialnih zavodov Slovenije.

Kavšek, M. \& Bogataj, D. (2016) Ageing in place driving urban transformations. Journal of Universal Excellence, 5(1), p. 1.

Keenan, T. A. (2010) Home and community preferences of the 45+ population. Available at: http://assets.aarp.org/rgcenter/general/homecommunity-services-10.pdf (accessed 12 Jun. 2016).

Kučera, T. \& Burcin, B. (2010) Changing age structure of population as a challenge for local authorities: Population prospects for city district Prague 3. In: Kovács, Z. (ed.) Challenges of ageing in villages and cities: The central European experience, pp. 132-160. Szeged, Department of Economic and Social Geography, University of Szeged.

Miller, C. E., Tucker, A. W. \& Zemlin, R. A. (1960) Integer programming formulation of traveling salesman problems. Journal of the ACM (JACM), 7(4), pp. 326-329. DOI: 10.1145/321043.321046

OECD. (2015) Ageing in cities. Paris, OECD Publishing.

Rosta, A., Zimborás, B., Mészáros, Á. \& Kovács, S. (2014) Social map of Zalaegerszeg. Zalaegerszeg, Zalaegerszeg Municipality, Zalaegerszeg Family Services and Child Welfare Centre and Zalaegerszeg Care Centre.

Statistical Office of the European Communities. (2016) Population density. Available at: http://ec.europa.eu/eurostat/web/products-datasets/-/ tps00003 (accessed 12 Jun. 2016).

Szander, N., Ros-McDonnell, L. \& Bogataj, M. (2016) A feasible nurse routing plan for the elderly: Quality and spatial trade-offs. In: Jaca, C. \& Sainz, M. (eds.) Building bridges between researchers and practitioners. San Sebastian, Tecnun - University of Navarra.

Szirmai, V., Váradi, Z., Kovács, S. \& Schuchmann, J. (2010) The issue of ageing in large Hungarian urban regions. In: Kovács, Z. (ed.) Challenges of ageing in villages and cities: The central European experience, pp. 161-177. Szeged, Department of Economic and Social Geography, University of Szeged. 